\title{
Clinicopathological and prognostic significance of platelet-lymphocyte ratio (PLR) in gastric cancer: an updated meta- analysis
}

Xunlei Zhang ${ }^{1 \dagger}$, Wenjing Zhao ${ }^{2 \dagger}$, Yang Yu ${ }^{1+}$, Xue $\mathrm{Qi}^{4}$, Li Song ${ }^{1}$, Chenfei Zhang ${ }^{1}$, Guoxing $\mathrm{Li}^{3^{*}}$ and Lei Yang ${ }^{1 *}$ (D)

\begin{abstract}
Background: Pre-treatment PLR (platelet-lymphocyte ratio) was reported to be associated with the prognosis in gastric cancer (GC), but the results remain inconclusive. This meta-analysis aimed to investigate the prognostic potential of the pre-treatment PLR in gastric cancer.

Methods: We performed a systematic literature search in PubMed, Embase, and the Cochrane Library to identify eligible publications. The hazard ratio (HR)/odds ratio (OR) and its 95\% confidence (Cl) of survival outcomes and clinicopathological parameters were calculated.

Results: A total of 49 studies (51 cohorts), collecting data from 28,929 GC patients, were included in the final analysis. The pooled results demonstrated that the elevated pre-treatment PLR was significantly associated with poor overall survival (OS) (HR 1.37, 95\% Cl 1.26-1.49, $\left.p<0.001 ; P^{2}=79.90 \%, P_{h}<0.001\right)$ and disease-free survival (DFS) (HR 1.52, 95\% Cl 1.22-1.90, $\left.p<0.001, P^{2}=88.6 \%, P_{\mathrm{h}}<0.001\right)$. Furthermore, the patients with the elevated PLR had a higher risk of lymph node metastasis $(\mathrm{OR}=1.17,95 \% \mathrm{Cl} 1.02-1.33, p=0.023)$, serosal invasion (T3+T4) $(\mathrm{OR}=$ $1.34,95 \% \mathrm{Cl} 1.10-1.64, p=0.003)$, and increased advanced stage (III+IV) (OR $=1.20,95 \% \mathrm{Cl} 1.06-1.37, p=0.004)$.

Conclusions: An elevated pre-treatment PLR was a prognostic factor for poor OS and DFS and associated with poor clinicopathological parameters in GC patients.
\end{abstract}

Keywords: Platelet, Lymphocyte, PLR, Gastric cancer, Meta-analysis

\section{Background}

Gastric cancer (GC) is a kind of common malignant tumor and one of the main causes of cancer-related mortality and morbidity worldwide [1]. Majority of the patients are diagnosed at an advanced stage due to no symptoms in the early stage. Complete or partial

\footnotetext{
* Correspondence: liguoxing1986@126.com; leiyang.53@163.com

'Xunlei Zhang, Wenjing Zhao and Yang Yu contributed equally to this work.

${ }^{3}$ Department of General Surgery, Tumor Hospital Affiliated to Nantong University, Nantong 226300, Jiangsu, China

'Department of Oncology, Tumor Hospital Affiliated to Nantong University, Nantong 226300, Jiangsu, China

Full list of author information is available at the end of the article
}

resection is the only potential curative treatment. However, the high recurrence and metastasis after resection lead to the poor level of 5-year survival rate [2]. For individual patients with different disease status and physical conditions who should receive individualized therapeutic regimens, it is essential to identify different risk groups according to various biomarkers. Therefore, potential biomarkers are required and crucial for predicting the patient prognosis and designing therapeutic regimen and follow-up scheme.

The systemic inflammatory response (SIR), being associated with the outcome of a variety of tumor-related 
inflammation, is considered an important component of tumor progression [3]. Immune and inflammatory cells in peripheral blood, such as neutrophils, lymphocytes, platelets, and monocytes, play important roles in the tumor micro-environment and relate to invasion and metastasis of tumor cells [4]. Some indexes of the SIRrelated cells, such as neutrophil to lymphocyte ratio (NLR), platelet-to-lymphocyte ratio (PLR), and monocyte to lymphocyte ratio (MLR), have been used to predict survival and recurrence of various cancers, including gastric cancer [5-8]. Among the indexes, PLR is considered a potential marker of endogenous residual anticancer pre-inflammatory and pre-coagulative response that arises in malignancies and is highly repeatable, cost-effective, and widely available $[9,10]$. The application of PLR in the diagnosis and prognosis of gastric cancer was also reported in a variety of studies but with controversial results. For example, Kim et al. found that elevated PLR predicted poor overall survival (OS) and disease-free survival (DFS) in GC patients after surgery [11]. However, some other studies did not detect the significant prognostic value of PLR for GC patients $[12,13]$. We conducted this meta-analysis to investigate the prognostic significance of pre-treatment PLR for OS and DFS, and the associations between PLR and clinicopathological features in GC patients.

\section{Materials and methods}

\section{Literature search}

We performed a systematic literature search in PubMed, Embase, and the Cochrane Library. The search strategy terms are as follows: (PLR or "platelet lymphocyte ratio" or "platelet-to-lymphocyte ratio" or "platelet-lymphocyte ratio") and ("gastric cancer" or "gastric adenocarcinoma" or "gastric carcinoma" or "GC" or "gastric neoplasm" or "stomach tumor" or "stomach neoplasm"). The last search was updated to April 8, 2020, and studies published in English were included. This study was conducted according to the Preferred Reporting Items for Systematic Reviews and Meta-Analyses (PRISMA) statement, and a flow chart of the systematic review is shown in Fig. 1. No ethical approval and patient consent are required in this study.

\section{Inclusion and exclusion criteria}

The predetermined inclusion and exclusion criteria were applied for the including of the articles in this study: Inclusion criteria are as follows: (1) the diagnosis must be confirmed by pathological examination; (2) HR and $95 \%$ $\mathrm{CI}$ for the OS and (or) DFS, the number of patients with various clinicopathological features are available; (3) PLR is the result of pre-treatment. Exclusion criteria are as follows: (1) conference abstracts, reviews, letters to the editor, and other nonclinical literature are not applied;
(2) articles with insufficient data to estimate are not included; and (3) the articles with non-human research or non-English language are not included.

\section{Data extraction and quality assessment}

All studies were assessed independently by two authors according to the designed eligibility criteria. Any questions or disagreements were resolved by consulting another co-author. The extracted data included the following study information: first author, publication year, country, study design (retrospective or prospective), study period, treatment regimens, follow-up time, cutoff value of PLR, and the number of patients with various clinicopathological features, including tumor location, differentiation, size, depths of tumor invasion, lymph node metastasis, TNM stage, and HRs with 95\% CIs of OS and DFS. The quality of each study was assessed according to the Newcastle-Ottawa Scale (NOS) by two authors [14] and a NOS score $\geq 6$ were considered high-quality researches.

\section{Statistical analysis}

The pooled HRs were calculated based on HRs and their 95\% CIs from each study to estimate prognostic role of PLR in GC patients. HRs and 95\% CIs for OS and DFS were obtained directly from each study if available or were calculated from the related data according to the methods published by Tierney et al. [15]. Cochran's $Q$ test and Higgins $I$-squared statistic were used to evaluate the heterogeneity of pooled results. A $p$ value $<0.1$ for the $Q$ test or $I^{2}>50 \%$ indicate significant heterogeneity among studies, and the random-effects model (DerSimonian-Laird method) was performed to calculate the pooled HRs. Otherwise, the fixed-effects model (MantelHaenszel method) was applied [16]. Odds ratios (OR) and 95\% CI were used to analyze the relationship between PLR and clinicopathological factors. Publication bias of the literature was evaluated by Begg's funnel plot and Egger's linear regression tests, and $p>0.05$ indicated that there was no significant publication bias. Sensitivity analysis was performed by removing each single study in turn to validate the stability of the pooled results. All statistical analyses were performed using STATA software version 14.0 (STATA Corporation, College Station, TX, USA). Results with $p<0.05$ were considered statistically significant, and all the results were two sided.

\section{Results}

\section{Study characteristics}

A total of 49 studies (51 cohorts) [7, 11-13, 17-61] with 28,929 GC patients were included in the final metaanalysis. As in Fan Feng's study [37], the GC patients were included in a training set and a validation set 


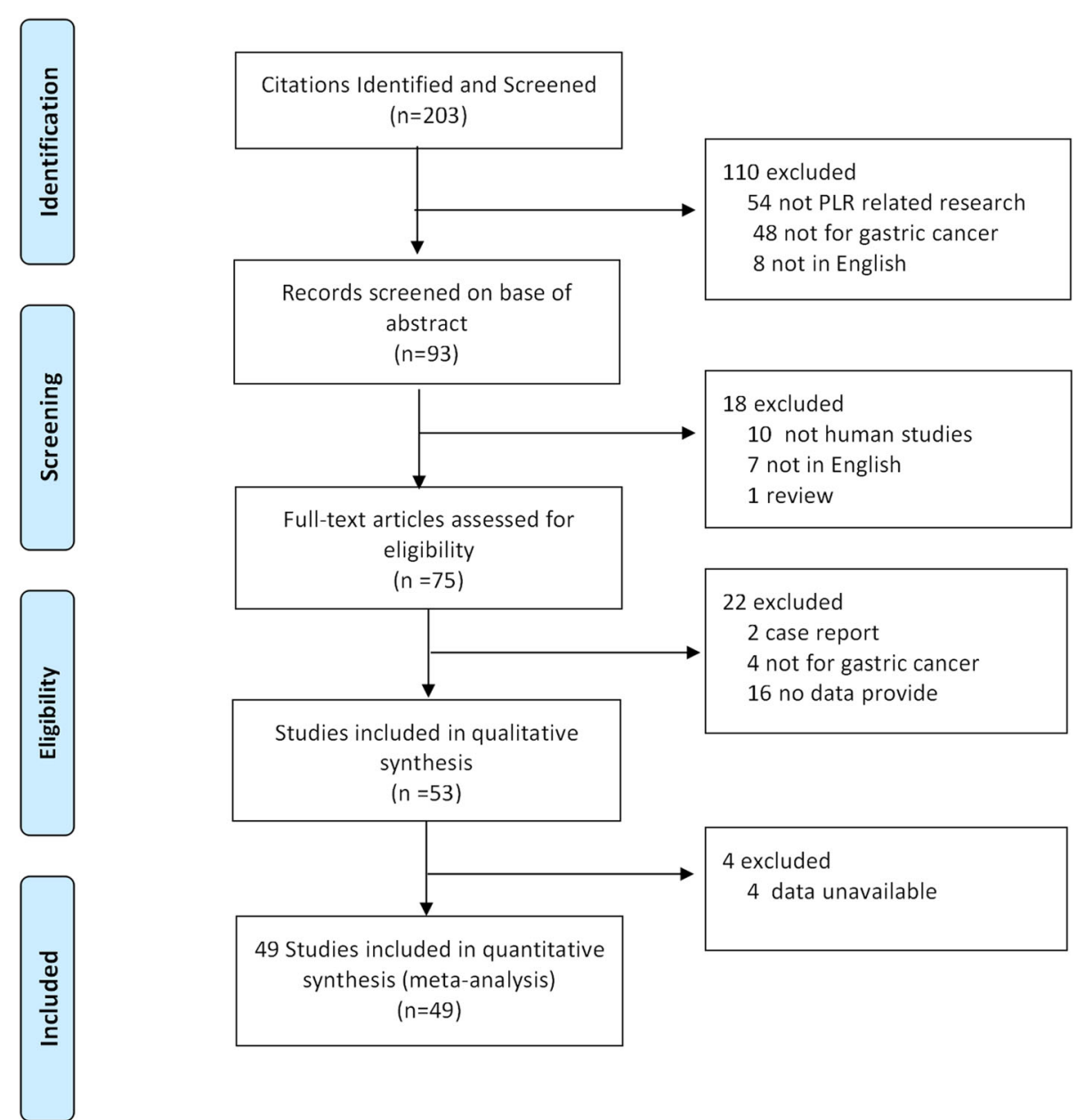

Fig. 1 The flow diagram of publications selection

independently; therefore, the two cohorts were extracted separately and named as Fan Feng(1) and Fan Feng(2). As in Aldemir's study, GC patients were divided into the surgery group and chemotherapy group. So we named the two groups as Aldemir(1) and Aldemir(2) [60]. The selection process of the included studies according to the PRISMA guidelines was shown in Fig. 1. We summarized the characteristics of the studies in Table 1. Among them, 10 studies were from Europe and the USA and 41 studies from Asia. The patients from 27 studies received surgery treatment, the patients with an advanced stage from 8 studies received chemotherapy strategy, and the patients from other 6 studied received mixed treatment (including chemotherapy, surgery, radiotherapy, targeted therapy, and supportive care). The cut-off values of PLR among the studies varied from 10.1 to 350 . Therefore, we selected PLR $=150$ to divide the studies in subgroup analysis. All studies with NOS scores $\geq 6$ were regarded as high-quality studies.

\section{PLR and prognosis of GC}

PLR in 44 cohorts with 26,901 GC patients were evaluated for OS [7, 11-13, 17, 19-27, 29-34, 37, 38, 41-51, 53-61]. The main results of this meta-analysis are listed in Table 2. We found that elevated PLR was significantly associated with a worse outcome for OS (HR 1.37, 95\% CI 1.26-1.49, $p<0.001$ ), and significant heterogeneity was observed $\left(I^{2}=79.90 \%, P_{\mathrm{h}}<0.001\right.$, Table 2, Fig. 2$)$.

All patients were stratified by ethnicity, treatment, cutoff value of PLR, and sample size for subgroup analysis. The results showed that elevated PLR had more significantly prognostic value for OS in Asian populations (HR 1.39, 95\% CI 1.28-1.52, $p<0.001 ; I^{2}=79.20 \%, P_{\mathrm{h}}<$ 0.001 ), but not in Caucasian populations. Furthermore, when different treatment methods were considered, elevated PLR significantly predicted shorter OS in patients receiving surgery treatment (HR 1.39, 95\% CI 1.26-1.52, $\left.p<0.001 ; I^{2}=79.10 \%, P_{\mathrm{h}}<0.001\right)$ but have no prognostic efficiency for patients receiving chemotherapy or 
Table 1 Characteristics of included studies in meta-analysis

\begin{tabular}{|c|c|c|c|c|c|c|c|c|c|c|}
\hline Author & Year & Country & Ethnicity & Treatment & $\begin{array}{l}\text { Follow-up } \\
\text { (month) }\end{array}$ & Cut-off & $\begin{array}{l}\text { Study } \\
\text { period }\end{array}$ & $\begin{array}{l}\text { Patients } \\
\text { (n) }\end{array}$ & $\begin{array}{l}\text { Survival } \\
\text { analysis }\end{array}$ & $\begin{array}{l}\text { NOS } \\
\text { score }\end{array}$ \\
\hline $\begin{array}{l}\text { Mehmet } \\
\text { Aliustaoglu }\end{array}$ & 2010 & Turkey & Caucasian & Chemotherapy & $\mathrm{NA}$ & 160 & $2004-2008$ & 168 & OS & 7 \\
\hline Deshen Wang & 2012 & China & Asian & Surgery & $39.9(23.77-57.43)$ & $\begin{array}{l}150 / \\
300\end{array}$ & $2006-2009$ & 324 & OS/DFS & 8 \\
\hline Suee Lee & 2013 & Korea & Asian & Chemotherapy & $14.9(1-47.9)$ & 160 & $2007-2010$ & 174 & OS & 7 \\
\hline Qing Wang & 2014 & China & Asian & Mixed & NA & 160 & 2006-2014 & 439 & OS & 7 \\
\hline Dawei Yuan & 2014 & China & Asian & Surgery & NA & 150 & 2009-2012 & 280 & OS/DFS & 7 \\
\hline Nan Jiang & 2014 & China & Asian & Surgery & $42(1-103)$ & 184 & $2005-2007$ & 377 & OS & 8 \\
\hline Lian Lian & 2015 & China & Asian & Surgery & 60 & 208 & $2007-2010$ & 162 & OS/DFS & 8 \\
\hline Fen Wang & 2015 & China & Asian & Chemotherapy & 40 & 235 & 2010-2011 & 120 & NA & 6 \\
\hline KaiYu Sun & 2015 & China & Asian & Surgery & $55.75(0.8-186)$ & 140 & $1998-2008$ & 632 & OS & 8 \\
\hline Xuechao Liu & 2015 & China & Asian & Surgery & NA & 180 & 2015-2010 & 455 & OS & 7 \\
\hline Meral Gunaldi & 2015 & Turkey & Caucasian & Mixed & 11.5 & 160 & NA & 245 & OS & 6 \\
\hline M. Messager & 2015 & UK & Caucasian & Surgery & $31.8(4-131)$ & 192 & $2001-2014$ & 153 & OS/DFS & 8 \\
\hline Qiwen Deng & 2015 & China & Asian & Surgery & $24(3-60)$ & 132 & $2007-2009$ & 389 & OS/DFS & 8 \\
\hline Jun-Te Hsu & 2015 & China & Asian & Surgery & 30 & 132 & $2005-2011$ & 1030 & OS & 8 \\
\hline Eun Young Kim & 2015 & Korea & Asian & Surgery & NA & 126 & 2000-2009 & 1986 & OS/DFS & 7 \\
\hline Aldemir(1) & 2015 & Turkey & Caucasian & Surgery & NA & 170 & 2006-2013 & 53 & OS & 7 \\
\hline Aldemir(2) & 2015 & Turkey & Caucasian & Chemotherapy & NA & 170 & 2006-2013 & 50 & OS & 7 \\
\hline Wenyang Pang & 2016 & China & Asian & Surgery & NA & 155.67 & 2009-2011 & 492 & NA & 6 \\
\hline Xin Zhou & 2016 & China & Asian & Surgery & NA & 167 & 2006-2008 & 451 & OS & 7 \\
\hline Jin Wang & 2016 & China & Asian & Chemotherapy & NA & 201.6 & 2005-2013 & 273 & OS & 7 \\
\hline Neng Lou & 2017 & China & Asian & Surgery & NA & 106 & 2006-2014 & 312 & NA & 6 \\
\hline Weipeng Gong & 2017 & China & Asian & Surgery & $22(8-67)$ & 161 & 2007-2015 & 91 & OS & 8 \\
\hline Kenichi Inaoka & 2017 & Japan & Asian & Surgery & NA & 71 & 1999-2016 & 312 & NA & 6 \\
\hline Masayuki Urabe & 2017 & Japan & Asian & Surgery & 63.3 & NA & 1999-2014 & 1363 & OS/DFS & 8 \\
\hline Shubin Song & 2017 & China & Asian & Surgery & $37(3-108)$ & 139.12 & 2007-2011 & 1990 & OS & 8 \\
\hline Fan Feng(1) & 2017 & China & Asian & Surgery & $24.9(1-75)$ & 130.675 & 2008-2015 & 1621 & OS & 8 \\
\hline Fan Feng(2) & 2017 & China & Asian & Surgery & $24.9(1-75)$ & 130.675 & 2008-2015 & 1622 & OS & 8 \\
\hline Kenji Mima Tsu & 2017 & Japan & Asian & Surgery & NA & 200 & 2006-2016 & 33 & OS & 7 \\
\hline Kang Wang & 2017 & China & Asian & Surgery & $45(1-185)$ & 120 & 1994-2005 & 444 & OS & 8 \\
\hline Harry E. Fuentes & 2017 & USA & Caucasian & Mixed & $21.3(9.5-42.6)$ & 260 & 2010-2015 & 112 & OS & 7 \\
\hline Mikito Mori & 2018 & Japan & Asian & Surgery & $37(5-108)$ & 149.4 & $2006-2017$ & 100 & NA & 7 \\
\hline Hongtai Shi & 2018 & China & Asian & Surgery & $36(1-75)$ & 135 & 2012-2014 & 688 & OS & 8 \\
\hline YuChen Pan & 2018 & China & Asian & Surgery & 59.9 & 115 & 2008-2012 & 870 & OS & 8 \\
\hline Guangsheng Zhu & 2018 & China & Asian & Surgery & NA & 117.78 & 2010-2016 & 248 & OS & 7 \\
\hline Hai-Jeon Yoon & 2018 & Japan & Asian & Surgery & $34.5(6.5-74.8)$ & 10.1 & 2011-2016 & 134 & OS/DFS & 8 \\
\hline Yan Zhang & 2018 & China & Asian & Mixed & NA & 172 & $2011-2014$ & 182 & OS/DFS & 7 \\
\hline $\mathrm{Ji}$ lin & 2018 & China & Asian & Surgery & NA & 116.85 & 2015-2016 & 670 & OS & 7 \\
\hline A. Ramos-Esquivel & 2018 & $\begin{array}{l}\text { Costa } \\
\text { Rica }\end{array}$ & Caucasian & Mixed & $13.21(0-84)$ & 350 & 2009-2012 & 381 & OS/DFS & 7 \\
\hline Jiaxin Wen & 2018 & UK & Caucasian & Surgery & NA & 150 & 2003-2015 & 668 & OS & 7 \\
\hline Angelica Petrillo & 2018 & Italy & Caucasian & Chemotherapy & $29(20.4-37.5)$ & 157 & 2010-2017 & 151 & OS & 8 \\
\hline Hiroaki Saito & 2018 & Japan & Asian & Surgery & NA & 173.3 & $2005-2013$ & 453 & OS & 7 \\
\hline
\end{tabular}


Table 1 Characteristics of included studies in meta-analysis (Continued)

\begin{tabular}{|c|c|c|c|c|c|c|c|c|c|c|}
\hline Author & Year & Country & Ethnicity & Treatment & $\begin{array}{l}\text { Follow-up } \\
\text { (month) }\end{array}$ & Cut-off & $\begin{array}{l}\text { Study } \\
\text { period }\end{array}$ & $\begin{array}{l}\text { Patients } \\
(\boldsymbol{n})\end{array}$ & $\begin{array}{l}\text { Survival } \\
\text { analysis }\end{array}$ & $\begin{array}{l}\text { NOS } \\
\text { score }\end{array}$ \\
\hline Cheng Tang & 2018 & China & Asian & Surgery & NA & 130.7 & 2010-2016 & 104 & OS & 7 \\
\hline Li-xiang Zhang & 2018 & China & Asian & Surgery & NA & 160 & 2010-2011 & 904 & OS & 7 \\
\hline $\begin{array}{l}\text { Osama Abu- } \\
\text { Shawer }\end{array}$ & 2019 & Jordan & Asian & Mixed & NA & 150 & NA & 447 & OS & 7 \\
\hline Xinran Zhang & 2019 & China & Asian & Surgery & $44.9(1-188.9)$ & 168.5 & 2000-2010 & 2752 & OS & 8 \\
\hline Cuixia Liu & 2019 & China & Asian & Surgery & NA & 152.2 & 2009-2012 & 400 & NA & 6 \\
\hline Hua-Long Zheng & 2019 & China & Asian & Surgery & $54(35-67)$ & 133.03 & 2009-2013 & 924 & OS & 8 \\
\hline Yuka Ohe & 2020 & Japan & Asian & Chemotherapy & NA & 180 & 2005-2018 & 41 & OS & 7 \\
\hline Ibrahim Mungan & 2020 & Turkey & Caucasian & Surgery & NA & 181.8 & 2015-2018 & 292 & NA & 6 \\
\hline Jian-Xian Lin & 2020 & China & Asian & Surgery & $65.6(1-117)$ & 162.5 & 2009-2014 & 2257 & OS & 8 \\
\hline Guanghui Zhao & 2020 & China & Asian & Chemotherapy & 11.6 & 143.39 & $2012-2016$ & 110 & OS & 8 \\
\hline
\end{tabular}

NA not available, OS overall survival, DFS disease-free survival, NOS Newcastle-Ottawa Scale

mixed treatment. Considering different cut-off values, both PLR with cut-off value $>150$ (HR 1.42, 95\% CI $\left.1.24-1.63, p<0.001 ; I^{2}=78.50 \%, P_{\mathrm{h}}<0.001\right)$ and $\leq 150$ (HR 1.36, 95\% CI 1.20-1.54, $p<0.001 ; I^{2}=75.00 \%, P_{\mathrm{h}}<$ 0.001 ) predicted poor OS for GC. Of note, we found that PLR, as a negative prognostic marker, was significantly associated with the OS in GC patients both in sample size $\leq 500$ groups (HR 1.42, 95\% CI 1.24-1.64, $p<0.001$; $\left.I^{2}=75.70 \%, P_{\mathrm{h}}<0.001\right)$ and $>500$ groups (HR 1.34, 95\% CI $1.20-1.50, p<0.001 ; I^{2}=85.00 \%, P_{\mathrm{h}}<0.001$; Table 2).

Ten studies with 5354 subjects explored the influence of PLR on DFS of GC patients [7, 11, 12, 20-22, 24, 26, $42,44,47]$. The pooled data of our meta-analysis indicated that the PLR was associated with DFS (HR 1.52, 95\% CI 1.22-1.90, $p<0.001, I^{2}=88.6 \%, P_{\mathrm{h}}<$ 0.001) (Table 2, Fig. 3).

\section{PLR and clinicopathological parameters of GC}

To further explore the impact of PLR on the clinicopathological parameters in GC, we extracted the number of patients from parts of studies in PLR-high and PLR-low groups according to the TNM stage, tumor differentiation, depth of invasion, tumor size, tumor location, and lymph node metastasis. As shown in Table 3, in comparison to low PLR groups, the high PLR groups had a higher risk of lymph node metastasis $(n=15$, OR $=1.17,95 \%$ CI 1.02 1.33, $p=0.023)$, serosal invasion $(\mathrm{T} 3+\mathrm{T} 4)(n=13$, OR $=$

Table 2 Main results of the meta-analysis

\begin{tabular}{|c|c|c|c|c|c|c|c|c|}
\hline & \multirow[t]{2}{*}{ Factors } & \multirow{2}{*}{$\begin{array}{l}\text { No. of } \\
\text { studies }\end{array}$} & \multirow{2}{*}{$\begin{array}{l}\text { No. of } \\
\text { patients }\end{array}$} & \multirow{2}{*}{$\begin{array}{l}\text { Effects } \\
\text { model }\end{array}$} & \multirow[t]{2}{*}{$\mathrm{HR}(95 \% \mathrm{Cl})$} & \multirow[t]{2}{*}{$p$} & \multicolumn{2}{|c|}{ Heterogeneity } \\
\hline & & & & & & & $\overline{I^{2}}$ & $P_{\mathrm{h}}$ \\
\hline \multirow[t]{14}{*}{ os } & Overall & 44 & 26901 & Random & $1.37(1.26-1.49)$ & $<0.001$ & $79.90 \%$ & $<0.001$ \\
\hline & \multicolumn{8}{|l|}{ Ethnicity } \\
\hline & Caucasian & 9 & 1981 & Random & $1.31(0.96-1.79)$ & 0.092 & $84.10 \%$ & $<0.001$ \\
\hline & Asian & 35 & 24920 & Random & $1.39(1.28-1.52)$ & $<0.001$ & $79.20 \%$ & $<0.001$ \\
\hline & \multicolumn{8}{|l|}{ Treatment } \\
\hline & Chemotherapy & 7 & 967 & Random & $1.34(0.96-1.88)$ & 0.084 & $76.10 \%$ & $<0.001$ \\
\hline & Surgery & 31 & 24128 & Random & $1.39(1.26-1.52)$ & $<0.001$ & $79.10 \%$ & $<0.001$ \\
\hline & Mixed & 6 & 1806 & Random & $1.38(0.98-1.93)$ & 0.062 & $88.20 \%$ & $<0.001$ \\
\hline & \multicolumn{8}{|l|}{ Cut-off } \\
\hline & $\leq 150$ & 20 & 15181 & Random & $1.36(1.20-1.54)$ & $<0.001$ & $75.00 \%$ & $<0.001$ \\
\hline & $>150$ & 23 & 10357 & Random & $1.42(1.24-1.63)$ & $<0.001$ & $78.50 \%$ & $<0.001$ \\
\hline & \multicolumn{8}{|l|}{ Sample size } \\
\hline & $\leq 500$ & 29 & 6924 & Random & $1.42(1.24-1.64)$ & $<0.001$ & $75.70 \%$ & $<0.001$ \\
\hline & $>500$ & 15 & 19977 & Random & $1.34(1.20-1.50)$ & $<0.001$ & $85.00 \%$ & $<0.001$ \\
\hline DFS & Overall & 10 & 5354 & Random & $1.52(1.22-1.90)$ & $<0.001$ & $88.60 \%$ & $<0.001$ \\
\hline
\end{tabular}




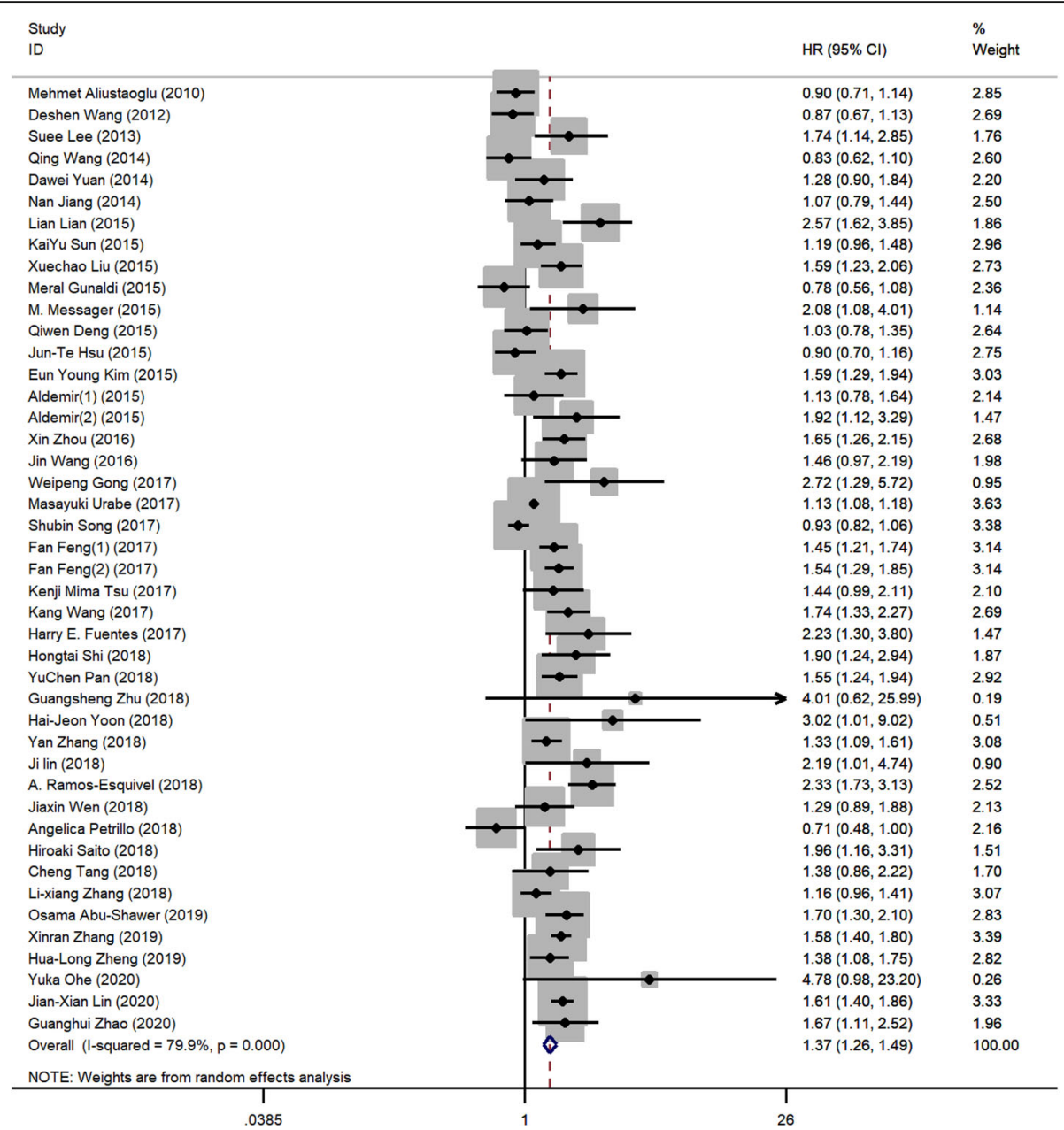

Fig. 2 The forest plot between elevated PLR and OS in GC patients

1.34, 95\% CI $1.10-1.64, p=0.003)$, and increased advanced stage $(\mathrm{III}+\mathrm{IV})(n=16, \mathrm{OR}=1.20,95 \%$ CI $1.06-$ 1.37, $p=0.004)$, whereas elevated PLR value was not shown to be associated with tumor size, tumor differentiation, and tumor location.

\section{Sensitivity analysis}

We performed sensitivity analysis for the OS by removing one single study at a time to check if individual study influenced the results. The corresponding pooled HRs are consistent, indicating stable and robust results in this meta-analysis (Fig. 4).

\section{Publication bias}

Begg's funnel plot and the Egger's linear regression test were performed to assess publication bias. The figure of the Begg's funnel plot showed obvious asymmetry (Fig. $5)$ and Egger's tests $(p=0.004)$ indicated significant publication bias. However, our finding that elevated PLR is associated with lower OS did not change after the adjustment for publication bias using the trim and fill method [62].

\section{Discussion}

The current meta-analysis was designed to investigate the prognostic value of elevated PLR for DFS and OS in GC patients. Pooled results demonstrated that elevated PLR was associated with poor OS and DFS. Moreover, elevated PLR was correlated with lymph node metastasis, serosal invasion, and advanced TNM stage with GC.

Despite the development of new surgical techniques and the use of chemotherapy and radiotherapy, gastric cancer still remains one of the main causes of cancerrelated mortality and morbidity worldwide [63]. Because individual GC patients present with different conditions, including different degrees of invasion, differentiation, and TNM stages, the survival outcomes may vary. Therefore, identification of reliable prognostic factors, simple and low cost, to stratify patients into different risk groups, would contribute to the optimization of 


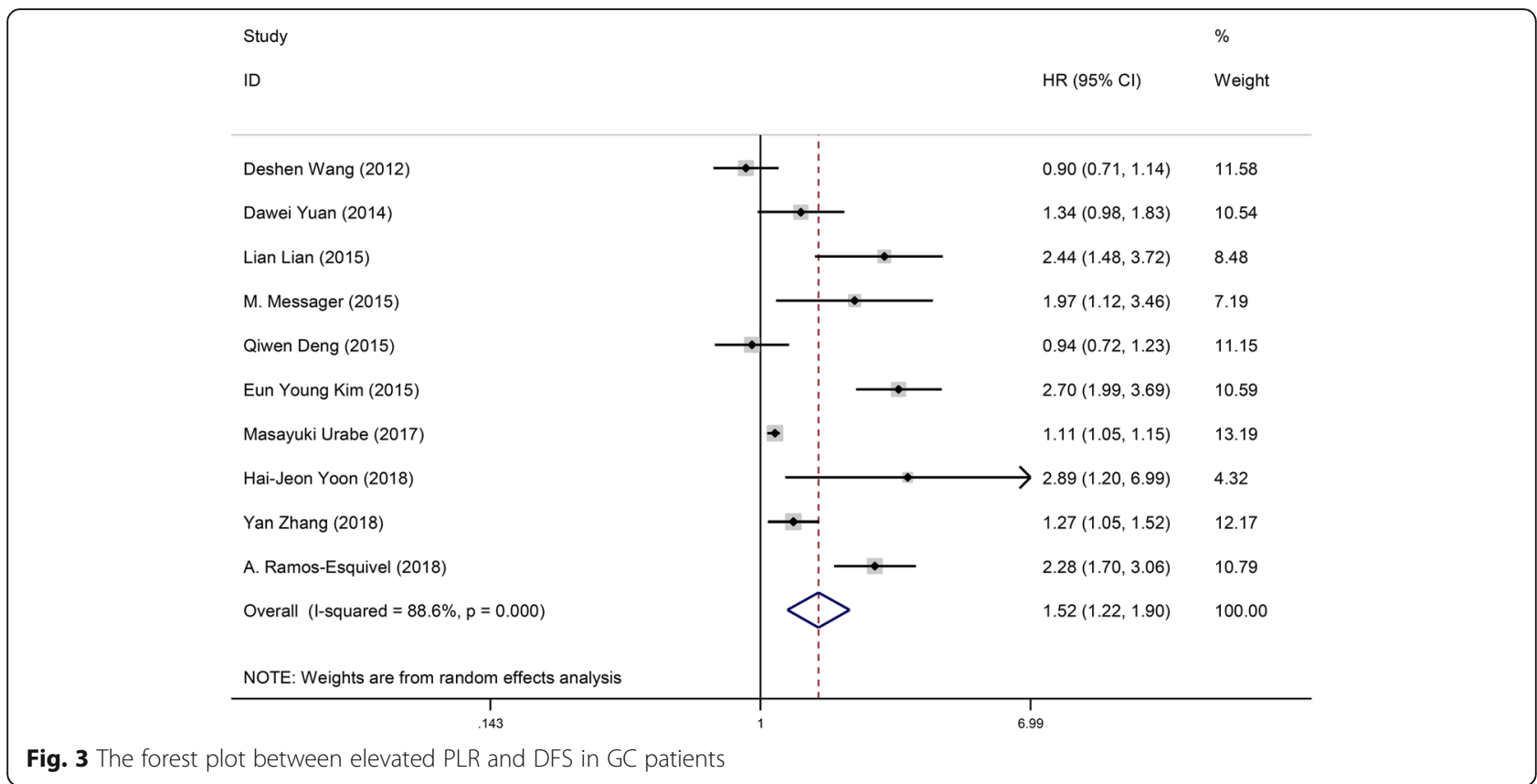

individualized treatment and follow-up. In recent years, the studies about the relationship between the inflammation and tumor have been developed. Inflammatory cells are critical factors in the tumor cell microenvironment and important for repair of tissue damage [64-66]. The inflammation is involved in lymphocytopenia, neutrophilia, thrombocytosis, and leukocytosis [67, 68]. The tumor-generated inflammatory reaction may contribute to tumor growth, progression, and metastasis through several mechanisms, including the upregulation of inflammatory mediators and cytokine, aberrant activation of immune regulatory cytokines, suppression of apoptosis, and DNA damage [65]. Recently, emerging evidence indicates that inflammatory reaction is an important factor for the initiation, progression, and prognosis of numerous cancers, including GC [69, 70]. Helicobacter pylori infection in GC is characterized by an inflammatory infiltrate, consisting mainly of neutrophils and T cells [71]. Moreover, circulating lymphocytes were reported that could reflect patient's inflammatory status [72]. Thus, some inflammation-based parameters, such as lymphocyte count, systemic immuneinflammation index (SII), platelet-lymphocyte ratio (PLR), and neutrophil-lymphocyte ratio (NLR), have been used to predict survival and recurrence in cancer patients [44, 73-76].

The PLR, which combines platelet and lymphocyte counts, is a representative index of systemic inflammation and immune status [77, 78]. Accumulating evidence indicates the correlation of PLR with different stages of tumor development, chemotherapeutic response, and prognostic survival outcomes of GC patients [38, 42, 78]. The specific mechanisms involved are complex and remain unclear. One potential explanation is that a decreased PLR may reflect tumor disadvantage status, such as inflammatory status, immune disorders, malnutrition, and a tendency for micro-vessel thrombosis [39, 79]. Lymphocytes have an important role in cancer immune surveillance and preventing the development of malignancy [80]. A

Table 3 Meta-analysis of the association between PLR and clinicopathological parameters of GC

\begin{tabular}{|c|c|c|c|c|c|c|c|}
\hline \multirow[t]{2}{*}{ Variable } & \multirow{2}{*}{$\begin{array}{l}\text { No. of } \\
\text { studies }\end{array}$} & \multirow{2}{*}{$\begin{array}{l}\text { No. of } \\
\text { patients }\end{array}$} & \multirow{2}{*}{$\begin{array}{l}\text { Effects } \\
\text { model }\end{array}$} & \multirow[t]{2}{*}{ OR $(95 \% \mathrm{Cl})$} & \multirow[t]{2}{*}{$p$} & \multicolumn{2}{|c|}{ Heterogeneity } \\
\hline & & & & & & $P^{2}$ & $P_{\mathrm{h}}$ \\
\hline Tumor differentiation (moderate/high vs. poor) & 18 & 6721 & Fixed & $1.04(0.98-1.11)$ & 0.173 & $7.30 \%$ & 0.367 \\
\hline Tumor location (cardia vs. non-cardia) & 10 & 2905 & Fixed & $0.99(0.87-1.12)$ & 0.837 & $6.00 \%$ & 0.386 \\
\hline Tumor size $(\leq 5 \mathrm{vs} .>5 \mathrm{~cm})$ & 8 & 2596 & Random & $1.04(0.88-1.23)$ & 0.634 & $74.20 \%$ & $<0.001$ \\
\hline Lymph node metastasis (no vs. yes) & 15 & 6752 & Random & $1.17(1.02-1.33)$ & 0.023 & $71.90 \%$ & $<0.001$ \\
\hline Depth of invasion (T1-T2 vs. T3-T4) & 13 & 6250 & Random & $1.34(1.10-1.64)$ & 0.003 & $86.20 \%$ & $<0.001$ \\
\hline TNM (Tis-II vs. III-IV) & 16 & 6834 & Random & $1.20(1.06-1.37)$ & 0.004 & $77.30 \%$ & $<0.001$ \\
\hline
\end{tabular}

OR odds ratio, $95 \% \mathrm{Cl} 95 \%$ confidence interval, $P_{h} p$ values of $Q$ test for heterogeneity test 


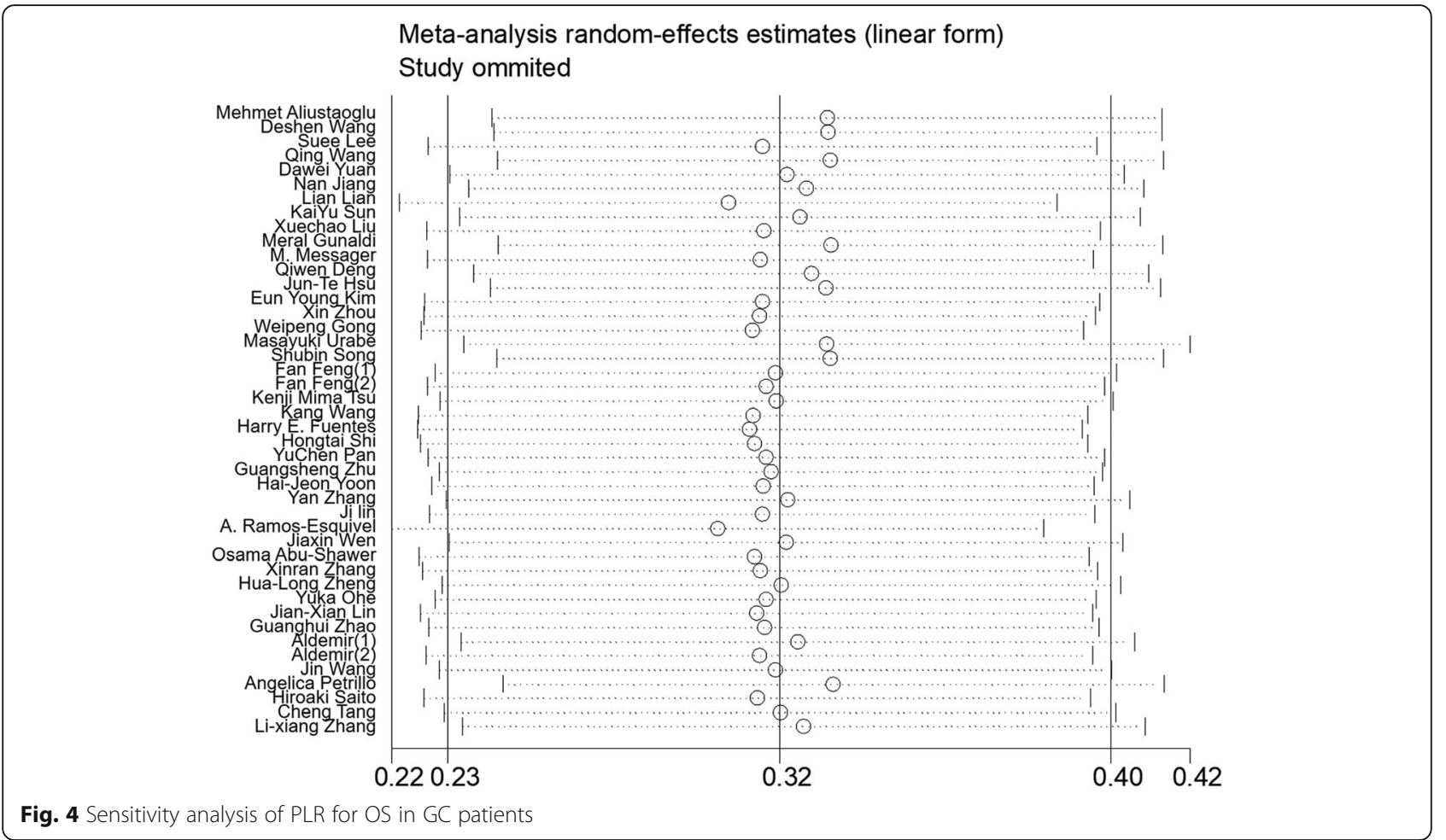

pro-inflammatory status leads to compromised cellmediated immunity and impaired T-lymphocytic response via cytokines [81]. The decrease in CD4+ Thelper lymphocytes may result in a suboptimal lymphocyte-mediated immune response to tumor cells [82]. The T-lymphocytic cell-mediated malnutrition is a major cause of delayed wound healing [83, 84].
Platelet count is an additional index of a systemic inflammatory response and potential micro-vessel thrombosis, which could inhibit wound healing via the deterioration of blood circulation in tissues [11, 77, 85]. Otherwise, aggregated platelets can promote tumor growth via releasing pro-angiogenic mediators within the micro-vasculature of tumors [86]. Platelets also

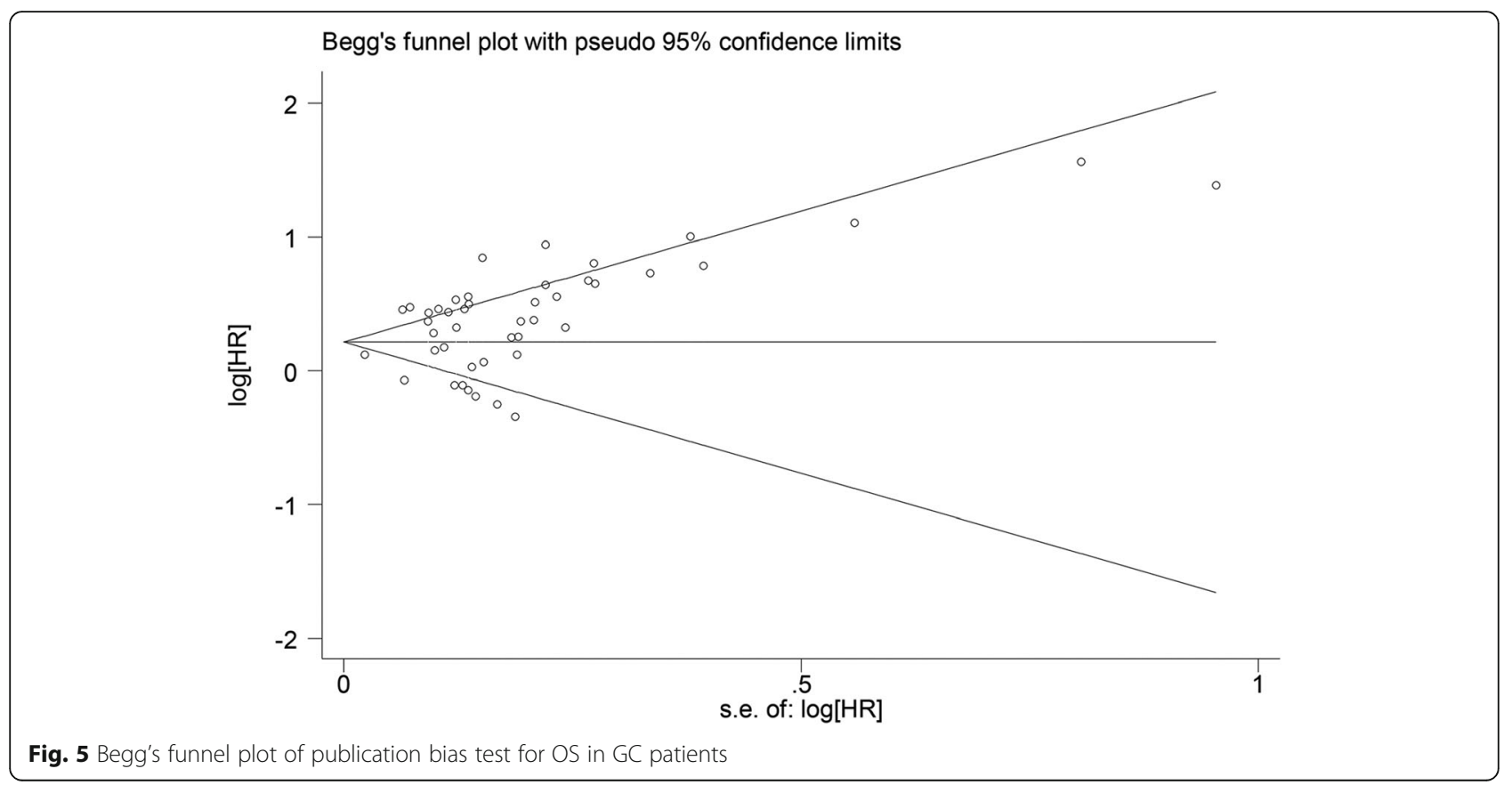


inhibit tumor cell extravasation by potentiating tumor cell-induced endothelial cell retraction, and enhance tumor cell adhesion and spreading across the extracellular matrix, which contribute to the promotion of tumor cell proliferation and metastasis [87]. Therefore, lymphocytopenia and thrombocytosis are considered negative prognostic markers in various cancers [88-91]. However, a decreased lymphocyte count or an increased platelet count alone may not reflect the host systemic inflammatory response and tumorigenesis process. Thus, the PLR, a biomarker combining platelet and lymphocyte counts, may better reflect the information of lymphocytopenia and thrombocytosis and predict the prognosis of GC patients. In addition, the value of PLR could be acquired from the routine laboratory tests, which provides clinical implications at a low cost.

Accumulated studies have assessed the association between PLR and the diagnosis and prognosis of gastric cancer. Some studies showed that elevated PLR predicted poor OS and DFS in GC patients after surgery $[22,24]$. However, some other studies did not detect the significant prognostic value of PLR for GC patients [7, 47]. Lian et al. reported that low PLR levels correlated with better clinicopathological features, including decreased depth of invasion, less lymph node metastasis, and early tumor stage [44]. Recently, a meta-analysis containing 8 studies comprising 4513 patients was conducted and showed that PLR was not a reliable predictor for OS in patients with GC, while another meta-analysis including 13 studies with 6280 patients indicated that elevated PLR could be a significant prognostic biomarker for poor OS $[92,93]$. Thus, the prognostic value of the PLR remains inconclusive in gastric cancer. So we conducted this updated meta-analysis to evaluate the prognostic role of the PLR in gastric cancer.

In the current study, including 49 studies (51 cohorts) with 28,929 GC patients, we not only investigated the prognostic value of PLR for OS and DFS, but also explored the associations between PLR and clinicopathological characteristics of GC. This analysis demonstrated that elevated PLR leads to a higher risk of lymph node metastasis, increased serosal invasion (T3+T4) risk, and advanced stage (III+IV) in patients with gastric cancer. Although the specific mechanism is still incompletely understood, our results are in accordance with other studies in various cancers, such as pancreatic ductal adenocarcinoma, hepatocellular carcinoma, and colorectal cancer [94-98].

Previous meta-analysis did not find significant association between PLR and OS or DFS in GC, maybe because of the limited studies included [92, 93]. Our metaanalysis including much more studies suggested that elevated PLR might have powerful prognostic efficiency for poor OS in GC and could predict shorter DFS in GC. Subgroup analyses for OS revealed the similar result in
Asian populations, but not in Caucasian populations. Moreover, we also eliminated the effect of different treatment methods on the prognostic value of the PLR. Our results showed that elevated PLR significantly predicted shorter OS in patients receiving surgery treatment, but did not have prognostic efficiency for patients receiving chemotherapy or mixed treatment. Except for the reason of too few studies included, another possible major reason is that the patients in the chemotherapy or mixed groups have huge differences in medical conditions and disease status, resulting in the inability to obtain significant results. To evaluate the effect of different cut-off values on the prognostic value of PLR in GC patients, subgroup analyses showed that patients with elevated PLR suffered worse OS than those with low PLR, regardless of the different cut-off values. The same effects were indicated in the subgroup analyses by different sample size of patients. These results might strengthen the possibility that PLR could act as a reliable prognostic biomarker in GC.

There were some limitations requiring to be addressed in this meta-analysis. First, the inclusion criteria of this meta-analysis were constrained to studies published in the English language only. So publication bias cannot be excluded. Second, almost the studies included were all retrospective, which could be more susceptible to some biases. Fortunately, the asymmetry in the funnel plots showed no significant publication bias, thus maintaining the substantial consistency of the results. Third, the different cut-off values of PLR used in each study could contribute to the heterogeneity. Subgroup analysis was conducted based on the different PLR cut-off values, while the results were not substantially changed. Further well-designed studies, especially randomized controlled trials (RCTs), are needed to determine the most appropriate cut-off value of PLR to predict the complication risks and survival outcomes in patients with GC.

\section{Conclusions}

In conclusion, elevated pre-treatment PLR is a prognostic factor for poor OS and DFS in GC patients. Furthermore, elevated PLR is correlated with a higher risk of serosal invasion, lymph node metastasis, and advanced TNM stage (III+IV) in gastric cancer. The present study suggests that the PLR could provide reliable information before treatment for patients with gastric cancer.

\footnotetext{
Abbreviations

HR: Hazard ratio; OR: Odds ratio; 95\% Cl: 95\% Confidence interval; $P_{\mathrm{h}}: P$ values of $Q$ test for heterogeneity test; OS: Overall survival; DFS: Disease-free survival; PLR: Platelet-lymphocyte ratio; GC: Gastric cancer; SIR: Systemic inflammatory response; NLR: Neutrophil to lymphocyte ratio; MLR: Monocyte to lymphocyte ratio; NOS: Newcastle-Ottawa Scale
} 


\section{Authors' contributions}

$X Z, W Z$, and $Y Y$ were involved in drafting the manuscript. $X Q$ and $L S$ made contributions to the concepts, acquisition, and analysis of the data. CZ was involved in acquisition of data and preparing the figures. $L Y$ and $G L$ designed and revised the manuscript. All authors have read and approved the final manuscript.

\section{Funding}

The work was supported by Youth Research Fund Project of the Health and Family Planning Commission of Nantong (WQ2015052) and the Project for Medical Key Youth Talent of Nantong (Youth 005).

\section{Availability of data and materials}

All data for this study are publicly available and are ready for the public to download at no cost from the official websites of the PubMed, EMBASE, and the Cochrane Library. There is no need to have the formal permission to use data for this study. The sources and data robustness have been described in the "Materials and methods" section.

\section{Ethics approval and consent to participate}

All the data supporting our findings in this paper were freely downloaded from the PubMed, EMBASE, and the Cochrane Library. No ethical approval or written informed consent for participation was required.

\section{Consent for publication}

Not applicable.

\section{Competing interests}

The authors declare that they have no competing interests.

\section{Author details}

'Department of Oncology, Tumor Hospital Affiliated to Nantong University, Nantong 226300, Jiangsu, China. ${ }^{2}$ Cancer Research Center Nantong, Tumor Hospital Affiliated to Nantong University, Nantong 226300, Jiangsu, China. ${ }^{3}$ Department of General Surgery, Tumor Hospital Affiliated to Nantong University, Nantong 226300, Jiangsu, China. ${ }^{4}$ Department of Oncology, Nantong Liangchun Hospital of Traditional Chinese Medicine, Nantong 226300, Jiangsu, China.

\section{Received: 11 April 2020 Accepted: 7 July 2020}

Published online: 30 July 2020

\section{References}

1. Siegel RL, Miller KD, Jemal A. Cancer statistics, 2019. CA Cancer J Clin. 2019; 69(1):7-34.

2. Soerjomataram I, Lortet-Tieulent J, Parkin DM, Ferlay J, Mathers C, Forman D, Bray F. Global burden of cancer in 2008: a systematic analysis of disabilityadjusted life-years in 12 world regions. Lancet. 2012:380(9856):1840-50.

3. McMillan DC. Systemic inflammation, nutritional status and survival in patients with cancer. Curr Opin Clin Nutr Metab Care. 2009:12(3):223-6.

4. Hainaut $P$, Plymoth $A$. Targeting the hallmarks of cancer: towards a rational approach to next-generation cancer therapy. Curr Opin Oncol. 2013;25(1): $50-1$.

5. Ock CY, Nam AR, Lee J, Bang JH, Lee KH, Han SW, Kim TY, Im SA, Bang YJ, Oh DY. Prognostic implication of antitumor immunity measured by the neutrophil-lymphocyte ratio and serum cytokines and angiogenic factors in gastric cancer. Gastric Cancer. 2017;20(2):254-62.

6. Wang SC, Chou JF, Strong VE, Brennan MF, Capanu M, Coit DG. Pretreatment neutrophil to lymphocyte ratio independently predicts disease-specific survival in resectable gastroesophageal junction and gastric adenocarcinoma. Ann Surg. 2016;263(2):292-7.

7. Deng Q, He B, Liu X, Yue J, Ying H, Pan Y, Sun H, Chen J, Wang F, Gao T, et al. Prognostic value of pre-operative inflammatory response biomarkers in gastric cancer patients and the construction of a predictive model. J Transl Med. 2015;13:66

8. Li S, Lan X, Gao H, Li Z, Chen L, Wang W, Song S, Wang Y, Li C, Zhang H, et al. Systemic inflammation response index (SIRI), cancer stem cells and survival of localised gastric adenocarcinoma after curative resection. J Cancer Res Clin Oncol. 2017;143(12):2455-68.

9. Seretis C, Seretis F, Lagoudianakis E, Politou M, Gemenetzis G, Salemis NS. Enhancing the accuracy of platelet to lymphocyte ratio after adjustment for large platelet count: a pilot study in breast cancer patients. Int J Surg Oncol. 2012;2012:653608.

10. Proctor MJ, Morrison DS, Talwar D, Balmer SM, Fletcher CD, O'Reilly DS, Foulis AK, Horgan PG, McMillan DC. A comparison of inflammation-based prognostic scores in patients with cancer. A Glasgow Inflammation Outcome Study. Eur J Cancer. 2011:47(17):2633-41.

11. Kim EY, Lee JW, Yoo HM, Park CH, Song KY. The platelet-to-lymphocyte ratio versus neutrophil-to-lymphocyte ratio: which is better as a prognostic factor in gastric cancer? Ann Surg Oncol. 2015;22(13):4363-70.

12. Wang DS, Ren C, Qiu MZ, Luo HY, Wang ZQ, Zhang DS, Wang FH, Li YH, Xu $\mathrm{RH}$. Comparison of the prognostic value of various preoperative inflammation-based factors in patients with stage III gastric cancer. Tumour Biol. 2012;33(3):749-56.

13. Aliustaoglu M, Bilici A, Ustaalioglu BB, Konya V, Gucun M, Seker M, Gumus $M$. The effect of peripheral blood values on prognosis of patients with locally advanced gastric cancer before treatment. Med Oncol. 2010;27(4): 1060-5.

14. Stang A. Critical evaluation of the Newcastle-Ottawa scale for the assessment of the quality of nonrandomized studies in meta-analyses. Eur J Epidemiol. 2010;25(9):603-5.

15. Tierney JF, Stewart LA, Ghersi D, Burdett S, Sydes MR. Practical methods for incorporating summary time-to-event data into meta-analysis. Trials. 2007;8:16.

16. Mantel N, Haenszel W. Statistical aspects of the analysis of data from retrospective studies of disease. J Natl Cancer Inst. 1959;22(4):719-48.

17. Zhang $X$, Hu D, Lin X, Zhang H, Xia Y, Lin J, Zheng X, Peng F, Jie J, Niu W. Prognostic value of an inflammation-related index in 6,865 Chinese patients With postoperative digestive tract cancers: The FIESTA Study. Front Oncol. 2019;9:427.

18. Liu C, Li X. Stage-Dependent Changes in Albumin, NLR, PLR, and AFR are Correlated with shorter survival in patients with gastric cancer. Clin Lab. 2019;65(9).

19. Abu-Shawer O, Abu-Shawer M, Haimour A, Alhouri A, Alkhatib AA, Abki M, Alqaisi O, Hamdan O, Alsaqri R, Ismail S, et al. Hematologic markers of distant metastases in gastric cancer. J Gastrointest Oncol. 2019;10(3):529-36.

20. Zhu GS, Tian SB, Wang H, Ma MG, Liu Y, Du HS, Long YP. Preoperative neutrophil lymphocyte ratio and platelet lymphocyte ratio cannot predict lymph node metastasis and prognosis in patients with early gastric cancer: a single institution investigation in China. Curr Med Sci. 2018;38(1):78-84.

21. Zhang Y, Lu JJ, Du YP, Feng CX, Wang LQ, Chen MB. Prognostic value of neutrophil-to-lymphocyte ratio and platelet-to-lymphocyte ratio in gastric cancer. Medicine (Baltimore). 2018;97(12):e0144.

22. Yoon HJ, Kim BS, Moon CM, Yoo J, Lee KE, Kim Y. Prognostic value of diffuse splenic FDG uptake on PET/CT in patients with gastric cancer. PLoS One. 2018:13(4):e0196110.

23. Wen J, Bedford M, Begum R, Mitchell H, Hodson J, Whiting J, Griffiths E. The value of inflammation based prognostic scores in patients undergoing surgical resection for oesophageal and gastric carcinoma. J Surg Oncol. 2018;117(8):1697-707.

24. Urabe M, Yamashita H, Watanabe T, Seto Y. Comparison of prognostic abilities among preoperative laboratory data indices in patients with resectable gastric and esophagogastric junction adenocarcinoma. World J Surg. 2018;42(1):185-94.

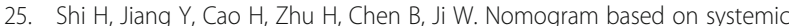
immune-inflammation index to predict overall survival in gastric cancer patients. Dis Markers. 2018;2018:1787424.

26. Ramos-Esquivel A, Cordero-Garcia E, Brenes-Redondo D, Alpizar-Alpizar W. The neutrophil-lymphocyte ratio is an independent prognostic factor for overall survival in Hispanic patients with gastric adenocarcinoma. J Gastrointest Cancer. 2018.

27. Pan YC, Jia ZF, Cao DH, Wu YH, Jiang J, Wen SM, Zhao D, Zhang SL, Cao XY Preoperative lymphocyte-to-monocyte ratio (LMR) could independently predict overall survival of resectable gastric cancer patients. Medicine (Baltimore). 2018;97(52):e13896.

28. Mori M, Shuto K, Kosugi C, Narushima K, Hayashi H, Matsubara H, Koda K. An increase in the neutrophil-to-lymphocyte ratio during adjuvant chemotherapy indicates a poor prognosis in patients with stage II or III gastric cancer. BMC Cancer. 2018;18(1):1261

29. Lin J, Zhang W, Huang Y, Chen W, Wu R, Chen X, Lou N, Wang P. Sarcopenia is associated with the neutrophil/lymphocyte and platelet/ lymphocyte ratios in operable gastric cancer patients: a prospective study. Cancer Manag Res. 2018;10:4935-44. 
30. Gong W, Zhao L, Dong Z, Dou Y, Liu Y, Ma C, Qu X. After neoadjuvant chemotherapy platelet/lymphocyte ratios negatively correlate with prognosis in gastric cancer patients. J Clin Lab Anal. 2018;32(5):e22364.

31. Fuentes HE, Oramas DM, Paz LH, Wang Y, Andrade XA, Tafur AJ. Venous thromboembolism is an independent predictor of mortality among patients with gastric cancer. J Gastrointest Cancer. 2018;49(4):415-21.

32. Wang K, Diao F, Ye Z, Zhang X, Zhai E, Ren H, Li T, Wu H, He Y, Cai S, et al. Prognostic value of systemic immune-inflammation index in patients with gastric cancer. Chin J Cancer. 2017;36(1):75.

33. Song S, Li C, Li S, Gao H, Lan X, Xue Y. Derived neutrophil to lymphocyte ratio and monocyte to lymphocyte ratio may be better biomarkers for predicting overall survival of patients with advanced gastric cancer. Onco Targets Ther. 2017;10:3145-54.

34. Mimatsu K, Fukino N, Ogasawara Y, Saino Y, Oida T. Utility of inflammatory marker- and nutritional status-based prognostic factors for predicting the prognosis of stage IV gastric cancer patients undergoing non-curative surgery. Anticancer Res. 2017;37(8):4215-22.

35. Lou N, Zhang L, Chen XD, Pang WY, Arvine C, Huang YP, Zhuang CL, Shen $X$. A novel scoring system associating with preoperative platelet/ lymphocyte and clinicopathologic features to predict lymph node metastasis in early gastric cancer. J Surg Res. 2017;209:153-61.

36. Inaoka K, Kanda M, Uda H, Tanaka Y, Tanaka C, Kobayashi D, Takami H, Iwata N, Hayashi M, Niwa Y, et al. Clinical utility of the plateletlymphocyte ratio as a predictor of postoperative complications after radical gastrectomy for clinical T2-4 gastric cancer. World J Gastroenterol. 2017;23(14):2519-26.

37. Feng F, Sun L, Zheng G, Liu S, Liu Z, Xu G, Guo M, Lian X, Fan D, Zhang H. Low lymphocyte-to-white blood cell ratio and high monocyte-to-white blood cell ratio predict poor prognosis in gastric cancer. Oncotarget. 2017; 8(3):5281-91.

38. Zhou X, Xu L, Huang Z, Zhang L, Zhang H, Zhu W, Liu P. The hematologic markers as prognostic factors in patients with resectable gastric cancer. Cancer Biomark. 2016;17(3):359-67.

39. Pang W, Lou N, Jin C, Hu C, Arvine C, Zhu G, Shen X. Combination of preoperative platelet/lymphocyte and neutrophil/lymphocyte rates and tumor-related factors to predict lymph node metastasis in patients with gastric cancer. Eur J Gastroenterol Hepatol. 2016;28(5):493-502.

40. Wang F, Liu ZY, Xia YY, Zhou C, Shen XM, Li XL, Han SG, Zheng Y, Mao ZQ, Gong FR, et al. Changes in neutrophi//lymphocyte and platelet/lymphocyte ratios after chemotherapy correlate with chemotherapy response and prediction of prognosis in patients with unresectable gastric cancer. Oncol Lett. 2015;10(6):3411-8.

41. Sun KY, Xu JB, Chen SL, Yuan YJ, Wu H, Peng JJ, Chen CQ, Guo P, Hao YT, He YL. Novel immunological and nutritional-based prognostic index for gastric cancer. World J Gastroenterol. 2015;21(19):5961-71.

42. Messager M, Neofytou K, Chaudry MA, Allum WH. Prognostic impact of preoperative platelets to lymphocytes ratio (PLR) on survival for oesophageal and junctional carcinoma treated with neoadjuvant chemotherapy: a retrospective monocentric study on 153 patients. Eur J Surg Oncol. 2015;41(10):1316-23.

43. Liu X, Sun X, Liu J, Kong P, Chen S, Zhan Y, Xu D. Preoperative C-reactive protein/albumin ratio predicts prognosis of patients after curative resection for gastric cancer. Transl Oncol. 2015;8(4):339-45.

44. Lian L, Xia YY, Zhou C, Shen XM, Li XL, Han SG, Zheng Y, Mao ZQ, Gong FR, Wu MY, et al. Application of platelet/lymphocyte and neutrophil/ lymphocyte ratios in early diagnosis and prognostic prediction in patients with resectable gastric cancer. Cancer Biomark. 2015;15(6):899-907.

45. Hsu JT, Liao CK, Le PH, Chen TH, Lin CJ, Chen JS, Chiang KC, Yeh TS. Prognostic value of the preoperative neutrophil to lymphocyte ratio in resectable gastric cancer. Medicine (Baltimore). 2015;94(39):e1589.

46. Gunaldi M, Goksu S, Erdem D, Gunduz S, Okuturlar Y, Tiken E, Kahraman S, Inan YO, Genc TB, Yildirim M. Prognostic impact of platelet/lymphocyte and neutrophil/lymphocyte ratios in patients with gastric cancer: a multicenter study. Int J Clin Exp Med. 2015;8(4):5937-42.

47. Yuan D, Zhu K, Li K, Yan R, Jia Y, Dang C. The preoperative neutrophillymphocyte ratio predicts recurrence and survival among patients undergoing $\mathrm{RO}$ resections of adenocarcinomas of the esophagogastric junction. J Surg Oncol. 2014;1 10(3):333-40

48. Wang Q, Yang Y, Zhang YP, Zou Z, Qian X, Liu B, Wei J. Prognostic value of carbohydrate tumor markers and inflammation-based markers in metastatic or recurrent gastric cancer. Med Oncol. 2014;31(12):289.
49. Jiang N, Deng JY, Liu Y, Ke B, Liu HG, Liang H. The role of preoperative neutrophil-lymphocyte and platelet-lymphocyte ratio in patients after radical resection for gastric cancer. Biomarkers. 2014;19(6):444-51.

50. Lee S, Oh SY, Kim SH, Lee JH, Kim MC, Kim KH, Kim HJ. Prognostic significance of neutrophil lymphocyte ratio and platelet lymphocyte ratio in advanced gastric cancer patients treated with FOLFOX chemotherapy. BMC Cancer. 2013;13:350

51. Zhang LX, Wei ZJ, Xu AM, Zang JH. Can the neutrophil-lymphocyte ratio and platelet-lymphocyte ratio be beneficial in predicting lymph node metastasis and promising prognostic markers of gastric cancer patients? Tumor maker retrospective study. Int I Surg. 2018;56:320-7.

52. Mungan I, Dicle CB, Bektas S, Sari S, Yamanyar S, Cavus M, Turan S, Bostanci EB. Does the preoperative platelet-to-lymphocyte ratio and neutrophil-tolymphocyte ratio predict morbidity after gastrectomy for gastric cancer? Mil Med Res. 2020;7(1):9.

53. Lin JX, Wang ZK, Huang YQ, Xie JW, Wang JB, Lu J, Chen QY, Lin M, Tu RH, Huang ZN, et al. Dynamic changes in pre- and postoperative levels of inflammatory markers and their effects on the prognosis of patients with gastric cancer. J Gastrointest Surg. 2020.

54. Zheng HL, Lu J, Xie JW, Wang JB, Lin JX, Chen QY, Cao LL, Lin M, Tu RH, Huang $\mathrm{ZN}$, et al. Exploring the value of new preoperative inflammation prognostic score: white blood cell to hemoglobin for gastric adenocarcinoma patients. BMC Cancer. 2019;19(1):1127.

55. Ohe Y, Fushida S, Yamaguchi T, Kinoshita J, Saito H, Okamoto K, Nakamura K, Tajima H, Ninomiya I, Ohta T. Peripheral blood platelet-lymphocyte ratio is good predictor of chemosensitivity and prognosis in gastric cancer patients. Cancer Manag Res. 2020;12:1303-11.

56. Tang C, Cheng X, Yu S, Wang Y, Hou J, Li Q, Shen Z, Liu T, Cui Y. Platelet-tolymphocyte ratio and lymphocyte-to-white blood cell ratio predict the efficacy of neoadjuvant chemotherapy and the prognosis of locally advanced gastric cancer patients treated with the oxaliplatin and capecitabine regimen. Onco Targets Ther. 2018;11:7061-75.

57. Wang J, Qu J, Li Z, Che X, Liu J, Teng Y, Jin B, Zhao M, Liu Y, Qu X: Pretreatment platelet-to-lymphocyte ratio is associated with the response to first-line chemotherapy and survival in patients with metastatic gastric cancer. J Clin Lab Anal 2018, 32(1).

58. Saito H, Kono Y, Murakami Y, Shishido Y, Kuroda H, Matsunaga T, Fukumoto Y, Osaki T, Ashida K, Fujiwara Y. Prognostic significance of platelet-based inflammatory indicators in patients with gastric cancer. World J Surg. 2018; 42(8):2542-50.

59. Zhao G, Liu N, Wang S, Guo J, Song X, Qi Y, Qiu W, Lv J. Prognostic significance of the neutrophil-to-lymphocyte and platelet-to-lymphocyte ratio in patients with metastatic gastric cancer. Medicine (Baltimore). 2020; 99(10):e19405

60. Aldemir MN, Turkeli M, Simsek M, Yildirim N, Bilen Y, Yetimoglu H, Bilici M, Tekin SB. Prognostic value of baseline neutrophil-lymphocyte and plateletlymphocyte ratios in local and advanced gastric cancer patients. Asian Pac J Cancer Prev. 2015;16(14):5933-7.

61. Petrillo A, Laterza MM, Tirino G, Pompella L, Ventriglia J, Pappalardo A, Famiglietti V, Martinelli E, Ciardiello F, Orditura M, et al. Systemicinflammation-based score can predict prognosis in metastatic gastric cancer patients before first-line chemotherapy. Future Oncol. 2018;14(24):2493-505.

62. Duval S, Tweedie R. Trim and fill: a simple funnel-plot-based method of testing and adjusting for publication bias in meta-analysis. Biometrics. 2000; 56(2):455-63.

63. Miller KD, Nogueira L, Mariotto AB, Rowland JH, Yabroff KR, Alfano CM, Jemal A, Kramer JL, Siegel RL. Cancer treatment and survivorship statistics, 2019. CA Cancer J Clin. 2019;69(5):363-85.

64. Brigati C, Noonan DM, Albini A, Benelli R. Tumors and inflammatory infiltrates: friends or foes? Clin Exp Metastasis. 2002;19(3):247-58.

65. Balkwill F, Mantovani A. Inflammation and cancer: back to Virchow? Lancet. 2001;357(9255):539-45.

66. Coussens LM, Werb Z. Inflammation and cancer. Nature. 2002;420(6917): 860-7.

67. Shoda K, Komatsu S, Ichikawa D, Kosuga T, Okamoto K, Arita T, Konishi H, Morimura R, Murayama Y. Shiozaki A et al: [Thrombocytosis associated with poor prognosis in patients with gastric cancer]. Gan To Kagaku Ryoho. 2015; 42(12):1980-2

68. Chen Y, Zhang L, Liu WX, Liu XY. Prognostic significance of preoperative anemia, leukocytosis and thrombocytosis in chinese women with epithelial ovarian cancer. Asian Pac J Cancer Prev. 2015;16(3):933-9. 
69. Lee K, Hwang H, Nam KT. Immune response and the tumor microenvironment: how they communicate to regulate gastric cancer. Gut Liver. 2014;8(2):131-9.

70. Mantovani A, Allavena P, Sica A, Balkwill F. Cancer-related inflammation Nature. 2008;454(7203):436-44.

71. Amedei $A$, Munari $F$, Bella CD, Niccolai E, Benagiano M, Bencini $L$, Cianchi $F$, Farsi M, Emmi G, Zanotti G, et al. Helicobacter pylori secreted peptidyl prolyl cis, trans-isomerase drives Th17 inflammation in gastric adenocarcinoma. Intern Emerg Med. 2014;9(3):303-9.

72. Wang $L$, Shen $Y$. Imbalance of circulating T-lymphocyte subpopulation in gastric cancer patients correlated with performance status. Clin Lab. 2013; 59(3-4):429-33.

73. Li S, Xu X, Liang D, Tian G, Song S. He Y: [Prognostic value of blood neutrophil-to-lymphocyte ratio (NLR) and platelet-to-lymphocyte ratio (PLR) in patients with gastric cancer]. Zhonghua Zhong Liu Za Zhi. 2014;36(12): 910-5.

74. Feng JF, Huang $Y$, Chen QX. Preoperative platelet lymphocyte ratio $(P L R)$ is superior to neutrophil lymphocyte ratio (NLR) as a predictive factor in patients with esophageal squamous cell carcinoma. World J Surg Oncol. 2014;12:58.

75. Hu B, Yang XR, Xu Y, Sun YF, Sun C, Guo W, Zhang X, Wang WM, Qiu SJ Zhou J, et al. Systemic immune-inflammation index predicts prognosis of patients after curative resection for hepatocellular carcinoma. Clin Cancer Res. 2014;20(23):6212-22.

76. Hong X, Cui B, Wang M, Yang Z, Wang L, Xu Q. Systemic pmmuneinflammation pndex, based on platelet counts and neutrophil-lymphocyte ratio, is useful for predicting prognosis in small cell lung cancer. Tohoku J Exp Med. 2015;236(4):297-304.

77. Zhou X, Du Y, Huang Z, Xu J, Qiu T, Wang J, Wang T, Zhu W, Liu P. Prognostic value of PLR in various cancers: a meta-analysis. PLoS One. 2014; 9(6):e101119.

78. Cruz-Ramos M, Del Puerto-Nevado L, Zheng B, Lopez-Bajo R, Cebrian A Rodriguez-Remirez M, Garcia-Garcia L, Solanes-Casado S, Garcia-Foncillas J. Prognostic significance of neutrophil-to lymphocyte ratio and platelet-to lymphocyte ratio in older patients with metastatic colorectal cancer. J Geriatr Oncol. 2019:10(5):742-8

79. Moyes LH, Leitch EF, McKee RF, Anderson JH, Horgan PG, McMillan DC. Preoperative systemic inflammation predicts postoperative infectious complications in patients undergoing curative resection for colorectal cancer. Br J Cancer. 2009;100(8):1236-9.

80. Dunn GP, Old $\amalg$, Schreiber RD. The immunobiology of cancer immunosurveillance and immunoediting. Immunity. 2004:21(2):137-48.

81. Liu H, Wu Y, Wang Z, Yao Y, Chen F, Zhang H, Wang Y, Song $Y$. Pretreatment platelet-to-lymphocyte ratio (PLR) as a predictor of response to first-line platinum-based chemotherapy and prognosis for patients with non-small cell lung cancer. J Thorac Dis. 2013;5(6):783-9.

82. An X, Ding PR, Li YH, Wang FH, Shi YX, Wang ZQ, He YJ, Xu RH, Jiang WQ. Elevated neutrophil to lymphocyte ratio predicts survival in advanced pancreatic cancer. Biomarkers. 2010;15(6):516-22.

83. Kanda M, Mizuno A, Tanaka C, Kobayashi D, Fujiwara M, Iwata N, Hayashi M, Yamada S, Nakayama G, Fujii T, et al. Nutritional predictors for postoperative short-term and long-term outcomes of patients with gastric cancer. Medicine (Baltimore). 2016;95(24):e3781.

84. Kanda M, Fujii T, Kodera Y, Nagai S, Takeda S, Nakao A. Nutritional predictors of postoperative outcome in pancreatic cancer. Br J Surg. 2011;98(2):268-74.

85. Neal CP, Mann CD, Garcea G, Briggs CD, Dennison AR, Berry DP. Preoperative systemic inflammation and infectious complications after resection of colorectal liver metastases. Arch Surg. 2011;146(4):471-8.

86. Sierko E, Wojtukiewicz MZ. Platelets and angiogenesis in malignancy. Semin Thromb Hemost. 2004;30(1):95-108.

87. Honn KV, Tang DG, Crissman JD. Platelets and cancer metastasis: a causal relationship? Cancer Metastasis Rev. 1992;11(3-4):325-51.

88. Hutterer GC, Krieger D, Mrsic E, Pohlmann K, Bezan A, Stojakovic T, Pummer K, Zigeuner R, Pichler M. Preoperative leucocytosis, thrombocytosis and anemia as potential prognostic factors in non-metastatic renal cell carcinoma. Anticancer Res. 2015;35(6):3463-9.

89. Josa V, Krzystanek M, Eklund AC, Salamon F, Zarand A, Szallasi Z, Baranyai Z. Relationship of postoperative thrombocytosis and survival of patients with colorectal cancer. Int J Surg. 2015;18:1-6.

90. Digklia A, Voutsadakis IA. Thrombocytosis as a prognostic marker in stage III and IV serous ovarian cancer. Obstet Gynecol Sci. 2014;57(6):457-63.
91. Buergy D, Wenz F, Groden C, Brockmann MA. Tumor-platelet interaction in solid tumors. Int J Cancer. 2012;130(12):2747-60.

92. $X u Z, X u$ W, Cheng $H$, Shen W, Ying J, Cheng F. The prognostic role of the platelet-lymphocytes ratio in gastric cancer: a meta-analysis. PLoS One. 2016;11(9):e0163719

93. Gu X, Gao XS, Cui M, Xie M, Peng C, Bai Y, Guo W, Han L, Xiong W. Clinicopathological and prognostic significance of platelet to lymphocyte ratio in patients with gastric cancer. Oncotarget. 2016;7(31):49878-87.

94. Smith RA, Bosonnet L, Raraty M, Sutton R, Neoptolemos JP, Campbell F, Ghaneh P. Preoperative platelet-lymphocyte ratio is an independent significant prognostic marker in resected pancreatic ductal adenocarcinoma. Am J Surg. 2009;197(4):466-72.

95. Pinato DJ, Mauri FA, Ramakrishnan R, Wahab L, Lloyd T, Sharma R. Inflammation-based prognostic indices in malignant pleural mesothelioma. J Thorac Oncol. 2012:7(3):587-94.

96. Pinato DJ, Stebbing J, Ishizuka M, Khan SA, Wasan HS, North BV, Kubota K, Sharma R. A novel and validated prognostic index in hepatocellular carcinoma: the inflammation based index (IBI). J Hepatol. 2012;57(5):1013-20.

97. Carruthers R, Tho LM, Brown J, Kakumanu S, McCartney E, McDonald AC. Systemic inflammatory response is a predictor of outcome in patients undergoing preoperative chemoradiation for locally advanced rectal cancer. Colorectal Dis. 2012:14(10):e701-7.

98. He W, Yin C, Guo G, Jiang C, Wang F, Qiu H, Chen X, Rong R, Zhang B, Xia $L$. Initial neutrophil lymphocyte ratio is superior to platelet lymphocyte ratio as an adverse prognostic and predictive factor in metastatic colorectal cancer. Med Oncol. 2013;30(1):439.

\section{Publisher's Note}

Springer Nature remains neutral with regard to jurisdictional claims in published maps and institutional affiliations.

Ready to submit your research? Choose BMC and benefit from:

- fast, convenient online submission

- thorough peer review by experienced researchers in your field

- rapid publication on acceptance

- support for research data, including large and complex data types

- gold Open Access which fosters wider collaboration and increased citations

- maximum visibility for your research: over $100 \mathrm{M}$ website views per year

At BMC, research is always in progress.

Learn more biomedcentral.com/submissions 